\title{
OTRA PIEDAD DE JACOB JORDAENS EN LA IGLESIA DE SANTO DOMINGO DE SANLÚCAR DE BARRAMEDA (CÁDIZ)
}

\author{
ANOTHER LAMMENTATION BY JACOB JORDAENS \\ AT SAINT DOMINIC CHURCH IN SANLÚCAR \\ DE BARRAMEDA (CÁDIZ)
}

\author{
Matías Díaz Padrón \\ Académie Royale d'Archéologie et d'Historie de l'Art de Belgique. Bégica-Instituto \\ Moll, Madrid. España \\ ORCID: 0000-0002-5137-7583 \\ matiasdiazpadron@gmail.com
}

\begin{abstract}
Este artículo da a conocer otra réplica de la Piedad de Jacob Jordaens del Museo del Prado. La obra, albergada en la iglesia de Santo Domingo de Sanlúcar de Barrameda (Cádiz), estaba considerada copia del siglo XVIII. Sin embargo, su calidad de ejecución y su relación con el ámbito sevillano, de donde procede también la pintura del Museo del Prado, permiten vincular este lienzo al pintor flamenco. Además, se aportan noticias más precisas del origen de la Piedad del Museo del Prado en el antiguo Oratorio de San Felipe Neri de Sevilla.

Palabras clave: Jacob Jordaens; Piedad; Sanlúcar de Barrameda; Museo del Prado; Sevilla.
\end{abstract}

This paper makes public a replica of the Jacob Jordaens's Lammentation in the Prado Museum. The work of art, housed at Saint Dominic Church in Sanlúcar de Barrameda (Cádiz), was considered as a copy from the $18^{\text {th }}$ century. However, the quality of its execution and its connection with the Sevillian field, from which also the painting in the Prado Museum comes, make it possible to link this canvas to the Flemish painter. Besides this, precise news about the origin of the Lammentation in the Prado Museum from the ancient Convent of Saint Philip Neri in Seville are contribute.

Keywords: Jacob Jordaens; Lammentation; Sanlúcar de Barrameda; Prado Museum; Seville.

En la segunda capilla de la nave de la epístola de la iglesia de Santo Domingo de Sanlúcar de Barrameda se encuentra un lienzo de la Piedad que ha

*Agradezco a Ana Diéguez-Rodríguez su colaboración en este artículo. 
pasado desapercibido hasta fechas relativamente recientes ${ }^{1}$ (Figura 1). El desconocimiento de esta pintura viene motivado, por un lado, por haber llegado a esta ubicación en un momento tardío, ya bien entrado el siglo XX, y, por otro, por no haberle prestado la suficiente atención a la calidad que delataban sus pinceladas, pues en últimos trabajos se recoge como copia de Jordaens del siglo XVIII².

No obstante, ya en 1985, Julio Ceballos fue el primero en advertir la calidad de la pintura ${ }^{3}$ y explicar su llegada a la iglesia dominica, procedente del antiguo colegio de los maristas de la ciudad, en cuyo salón-comedor la había visto. La pintura, en realidad, provenía de la capilla de la Hermandad de la Virgen del Rosario en San Juan de Aznalfarache (Sevilla). Tras el estallido de la Guerra Civil, en 1936, la hermandad la traslada a la iglesia de San Juan Bautista de la misma localidad sevillana, buscando preservarla de los tristes peligros de la guerra. En 1945, el cardenal Segura manda llevar el lienzo a la antigua aduana de Sanlúcar de Barrameda, por aquel entonces convertida en Instituto Eucarístico Diocesano. En 1954, este Instituto Eucarístico es vendido a los hermanos maristas para convertirlo en colegio y las obras que en él se guardan pasan a la localidad vecina de Jerez de la Frontera, a excepción de esta Piedad que pasa a la iglesia de Santo Domingo, donde hoy se encuentra.

Ceballos, guiado por su buen criterio e intuición, escribió al Museo de Prado, como narra en su artículo de 1985, buscando ratificación respecto a sus sospechas sobre la autoría. Las cartas solicitando atención a esta pintura las envió al entonces director del Museo del Prado, don Alfonso Pérez Sánchez. En respuesta, este le invitó a ponerse en contacto con el conservador de pintura flamenca de la pinacoteca madrileña, don Matías Díaz Padrón, pero esta notificación nunca llegó a su destino ${ }^{4}$. La llamada de atención de don Julio Ceballos tuvo repercusión en la prensa nacional y local ${ }^{5}$. En los comentarios que le dedica este estudioso y pintor natural de Chipiona (Cádiz) cabe el reconocimiento de vincular la pintura de

${ }^{1}$ MONTES, Francisco: "Anónimo (copia de Jacob Jordaens)", en La imagen reflejada. Andalucía, espejo de Europa (cat. exp.). Sevilla, 2007, p. 366.

${ }^{2}$ Ibidem.

${ }^{3}$ CEBALlOS, Julio: "Descendimiento de Jordaens", Chipiona Informativo, 16, 1985, p. 6.

${ }^{4}$ En carta del 21 de enero de 1984, don Julio Ceballos acusa recibo de la dirección del museo: "el conservador del museo del Prado de pintura flamenca, Matías Díaz Padrón, está ahora mismo estudiando las fotos en cuestión y ya le dará su opinión al respecto". Esto está transcrito en CEBALLOS, Julio: "Descendimiento...", op. cit., p. 7. El 30 de julio de 1984 continúa tratando el mismo asunto: "el gran lienzo del Descendimiento, según el juicio del señor Díaz Padrón, conservador de pintura flamenca del museo del Prado y autor de nuestro catálogo crítico, debe ser una réplica de taller del original de Jordaens que aquí se guarda". CEBALLOS, Julio: "Descendimiento...", op. cit., p. 8.

5 ABC, Sevilla, 1984; El Correo, 1986, respectivamente. 
la iglesia de Santo Domingo con la réplica del Museo del Prado [inv. nº P06392] (Figura 2).

Efectivamente, la pintura de Sanlúcar repite la escena de la Piedad del Museo del Prado, obra procedente de la iglesia de San Alberto de Sevilla ${ }^{6}$, como se creía que era su origen primero hasta ahora. Sin embargo, la pintura del Museo del Prado tiene su procedencia más antigua en el templo hispalense del Oratorio de San Felipe Neri, inmueble destruido por decreto de la junta revolucionaria de 1868. Allí lo cita el conde del Águila en sus anotaciones al Viaje de España de Ponz dedicado a Sevilla: "De Jordaens: El Descendimiento de la cruz en la parte superior del altar colateral de la Epístola (es muy dudoso)"’. La congregación filipense se trasladó a la iglesia del exclaustrado colegio de carmelitas calzados de San Alberto, que le fuera concedida por rescripto pontificio en 1893. Allí se encontraba la pieza en 1976, año en el que el Museo del Prado tiene constancia de esta pintura y la adquiere para su colección en $1981^{8}$.

Es curioso que dos localidades no muy distantes entre sí, Sevilla y San Juan de Aznalfarache, tuvieran dos pinturas con el mismo tema de la Piedad de Jacob Jordaens. En este sentido, no habría que desestimar como origen de ambas la importante afluencia de obras que a través del puerto hispalense llegaban a España, tanto para abastecer el mercado nacional como el destinado a América. En este sentido, es necesario recordar que en 1642, el mercader flamenco asentado en Madrid, Pedro van Vucht, está declarando entre sus bienes, con motivo de su enlace con Juana Lucía López Pueyo", una pintura "de nuestro señor Jesucristo descendimiento de la cruz de dos baras y media de alto y cerca de dos baras de ancho de mano de Juan Jordan en tres mil reales 3.000". Burke y Cherry ya relacionan la entrada con el trabajo de Jacob Jordaens por su alta tasación ${ }^{10}$. Por otro lado, el traspaso de las medidas expresadas en varas de este inventario a centímetros (220 x $175 \mathrm{~cm}$ aproximadamente) encajan con el formato del lienzo del Museo del Prado (L. 221 x 169 cm), y tampoco están lejos de la obra de Sanlúcar (L. 207 x $159 \mathrm{~cm}$ ), por lo que no sería extraño que esta pintura de Van Vucht pudiera haber terminado en algún convento de Sevilla o de sus aledaños.

${ }^{6}$ DÍAZ PADRÓN, Matías: "Una Piedad de Jacobo Jordaens en la Iglesia de San Alberto de Sevilla", Bulletin des Musées Royaux des Beaux-Arts de Belguique, 1974-1980, p. 199; y DÍAZ PADRÓN, Matías: "Piedad", en Pedro Pablo Rubens (cat. exp.). Madrid, 1977, p. $70, \mathrm{n}^{\circ} 53$.

7 CARRIAZO, Juan de Mata: "Correspondencia de don Antonio Ponz con el Conde del Águila”, Archivo Español de Arte y Arqueología, V, 1929, p. 177.

${ }^{8}$ DÍAZ PADRÓN, Matías: Museo del Prado. Adquisiciones de 1978 a 1981. Madrid, $1981, \mathrm{n}^{\circ} 13$.

9 BURKE, Marcus B. y CHERRY, Peter: Collections of Paintings in Madrid. Spanish Inventories (Parts 1 and 2). Los Ángeles, 1997, p. 365.

${ }^{10}$ Ibidem, p. 4. 
A pesar de los esfuerzos de Ceballos por buscar el interés de los estudiosos por la obra sanluqueña, no fue hasta la exposición La imagen reflejada. Andalucía, espejo de Europa organizada por la Junta de Andalucía ${ }^{11}$, cuando esta pintura vuelve a ser foco de atención. Montes la cataloga como copia de Jacob Jordaens, quizá del siglo XVIII ${ }^{12}$, atendiendo al original del Museo del Prado. Sin embargo, una mirada atenta a la pintura dentro de la capilla que la cobija, ha permitido advertir el modo de trabajo propio de Jordaens en la consecución de la calidad de los detalles y su tratamiento lumínico, que la aleja de la categoría de copia y la acerca a la de réplica por parte del mismo pintor.

La Virgen, que dirige una mirada suplicante hacia el cielo en el centro de la escena, domina la composición. Tiene en sus rodillas el cuerpo inerte de Jesús, tras haberlo descendido de la cruz. Ella asume toda la esencia del drama. El cuerpo desnudo de Jesús destaca frente al manto azul con el que la Virgen parece intentar mitigar su dolor de madre al tener entre sus brazos el cuerpo de su hijo muerto. El escorzo en el primer plano de la anatomía de Jesús, se destaca por la luz frontal. El sentido ebúrneo de las carnaciones aún se enfatiza más por los contrastes fuertes de color amarillo-dorado del vestido de la Magdalena, arrodillada al lado derecho extrayendo la corona de espinas ${ }^{13}$. Su posición, tomada de espaldas, no resta protagonismo al cuerpo de Jesús. Por otro lado, el manto rojo de San Juan evangelista, a la izquierda en pie, tras María de Cleofás, cierra esa diagonal donde los tres colores primarios son los protagonistas, resaltando el sentido de grisalla de toda la escena. María de Cleofás también está arrodillada a los pies de Cristo tomando la mano del maestro con sentido dolor. Hay un claro efectivo púdico del color para destacar la esencia divina y simbólica del escorzo de Cristo sobre el regazo de su madre. María es ahora la prefiguración de la Iglesia que lleva en su seno el sacrificio de Cristo y lo honra en cada celebración eucarística.

Identificamos a la Magdalena por la riqueza de su vestido y esmerado peinado; tanto ella como María de Cleofás están lavando y acicalando el cuerpo de Cristo, como prueba la jofaina y palangana del primer plano. Frente a la actividad femenina, en el segundo plano, San Juan entrelaza sus dedos con contenido dolor, mientras, en el lado contrario, Nicodemo y José de Arimatea lloran abiertamente la muerte del maestro. Se reconoce a este último por la riqueza de su manto. Era un hombre rico e influyente que consiguió permiso de Pilatos para enterrar a Cristo. Apoya su brazo en la escalera. Es un mismo modelo que Jordaens repite, idéntico, en el Martirio de Santa Apolonia, de la iglesia de San Agustín de

${ }^{11}$ MONTES, Francisco: “Anónimo (copia de Jacob Jordaens)”, op. cit., p. 366.

12 Posiblemente, el estimarla copia del XVIII se debe a haber sido asociada la cronología de la pintura con la de su marco, de evidente estilo Rococó. MONTES, Francisco: "Anónimo (copia de Jacob Jordaens)", op. cit., p. 366. Sin embargo, ni el estilo ni la técnica están en consonancia con el Siglo de las Luces.

13 MÂLE, Emile: L'art Religieux. París, 1932, p. 283. 
Amberes y en la Alegoría religiosa de la Bayerische Staatsgemäldesammlungen en el castillo Johannisburg de Aschaffenburg (Würzburg) (inv. $\mathrm{n}^{\circ}$ 6288). También para otros personajes, Jordaens retoma modelos que ha empleado en otras composiciones, es una constante a lo largo de su producción. Así, el modelo de San Juan lo repite en la Adoración de los pastores de Estocolmo, en el San Juan de Brujas y en el Sacrificio de Isaac de Breda. Para Nicodemo, vuelto de tres cuartos de perfil, utiliza el Retrato de Abraham Graef (Grapheus), un conocido personaje, amigo del pintor y destacado miembro de la guilda de pintores de la ciudad, que va a ser modelo de otros pintores como Rubens o Cornelis de $\operatorname{Vos}^{14}$.

Frente a la pintura del Museo del Prado, esta de Sanlúcar presenta unas tonalidades más grisáceas, dando a toda la escena una sensación de grisalla que rompe la concentración de los tonos primarios en los mantos y ropajes de los personajes en torno al cuerpo inerte de Cristo. En la versión del Museo del Prado los tonos son más brillantes y saturados. Esto no es merma para el ejemplar sanluqueño. El lienzo ha absorbido el barniz y es mucho más evidente la trama de la tela. Además, ciertos repintes, como el que se encuentra sobre el rostro de María de Cleofás, alteran la obra y parecen cambios significativos respecto a la del $\mathrm{Mu}-$ seo del Prado.

Jordaens trabaja el tema de la Piedad y la Lamentación en varias ocasiones a lo largo de su carrera. Se conserva el dibujo de la composición en la colección de Sir Richard Nosworthy ${ }^{15}$ (Figura 3). Parece que Jordaens limitó la altura al pasar a lienzo la escena, en caso de que no fuera una intervención posterior reduciendo el tamaño del lienzo en la parte alta, aspecto que también hay que tener en cuenta debido a las vicisitudes históricas que estas obras pudieron haber tenido. Jordaens cambia la postura de San Juan girando el rostro en tres cuartos en la versión definitiva, mientras que en el dibujo se ve que es más frontal. El cambio lo siguió en las repeticiones del Museo del Prado y de la Rubenshuis de Amberes (Figura 4).

Sobre la figura de San Juan, Jordaens va a trabajar de forma individualizada, lo que explica los cambios respecto a la composición final. Un dibujo de este personaje se guarda en el Fogg Art Museum, Cambrige, Harvard University ${ }^{16}$ (Figura 5), donde se aprecia el cambio en las manos con los dedos entrelazados por el dolor, como hace en los lienzos, variando la postura respecto al dibujo de la colección Nosworthy. Este diseño del Fogg Art Museum también presenta mayor contraste de luces y sombras. Esto se percibe mejor en las mejillas y en los pliegues del manto. No sería extraño que Jordaens trabajase expresiones y gestos de

14 JOUBERT, Caroline (dir.): Jacob Jordaens et son modéle Abraham Grapheus. Caen, 2012.

${ }_{15}$ D'HULST, R.-A.: Jordaens Drawings. Bruselas-Londres-Nueva York, 1974, IV, nº A279.

16 Ibidem, $\mathrm{n}^{\circ} \mathrm{A} 277$.

LABORATORIO DE ARTE 31 (2019), pp. 641-652, ISSN 1130-5762 e-ISSN 2253-8305 - DOI http://dx.doi.org/10.12795/LA.2019.i31.38 
forma individual para esta escena que no han llegado a nosotros. De hecho, las manos de Nicodemo en los lienzos también se diferencian en su posición respecto al dibujo de la colección Nosworthy. En el dibujo aprieta con fuerza las dos manos destacadas sobre el celaje, mientras que las repliega sobre el pecho en la pintura, dando mayor presencia al azul del celaje. Es posible que entre los estudios de expresiones para esta composición, además de la figura de San Juan, el rostro de la Virgen fuera ensayado en el dibujo de la antigua colección de A.G.B. Russell ${ }^{17}$ alzando su mirada suplicante hacia el cielo (Figura 6).

Jordaens hace que estos cambios sutiles que se advierten en la escena final respecto a su idea en el diseño incidan en la emotividad y sentido dramático del episodio representado. En las pinturas, los cabellos de San Juan parecen movidos por el viento, y el cielo, de nubarrones sombríos, acentúa el drama que viven los personajes.

Jordaens siguió las consignas de la Contrarreforma para idear esta composición ${ }^{18}$, a pesar de su conocida inclinación al protestantismo. Identifica en Cristo al niño que María llevaba en su regazo, fiel así a las meditaciones de Juan de Cartagena con la Virgen suplicante.

El pathos de la composición no es frecuente en el estilo de Jordaens. Esto observó Van Puyvelde al tratar las versiones citadas ${ }^{19}$. Esta acertada composición piramidal la debió de tomar de Van Dyck, que representa a la Virgen con los brazos abiertos, entregada al destino, en la composición de la Alte Pinakothek de Munich (inv. $n^{\circ}$ 606). La teatralidad y la distinción es más propia del estilo de Van Dyck, visible en composiciones tales como la versión de la Pinacoteca de Múnich de 1634 o la del Museo de Bellas Artes de Bilbao (inv. no 85-221). No obstante, los robustos personajes y la enérgica factura delatan la personalidad de Jordaens. No pretende asumir el colorido armonioso, la estilización ni la seducción sentimental de Van Dyck. Esto no es óbice para advertir ecos del modelo escultórico de La Piedad de Miguel Ángel, siguiendo grabados de la época. A esto se une el sentimiento barroco que manipula Rubens y que le lleva a idear una composición llena de diagonales que convergen en el centro simbólico de los dos personajes principales: la Virgen y Jesús.

Técnicamente, la pincelada jugosa de la materia aproxima este lienzo a los años de 1645-1650, época fecunda en la producción de Jordaens ${ }^{20}$, con un

17 Ibid., p. 357, n ${ }^{\circ}$ A277.
${ }_{18}$ Marcos (15, 42-47), Juan (19, 38-42) y Mateo (27, 57-60).
${ }_{19}$ VAN PUYVEDE, Leo: Jordaens. París-Bruselas, 1953, p. 105.
${ }_{20}$ D’HULST, R.-A.: Jacob Jordaens. Amberes, 1982, pp. 207-208. Es un momento en el que se ve obligado a recurrir al taller, pero la inmensa cantidad de sus obras están retocadas por el maestro; lo que difícilmente puede un crítico diferenciarlas de los originales de indiscutible autoría en épocas primeras. 
importante reclamo de sus obras en el extranjero. Esto se acusó por la muerte de Rubens y Van Dyck, a principios de los años 40 del siglo XVII.

Por estas fechas se exportan obras de Jordaens hacia zonas más meridionales. Varias pinturas, como la Piedad del Museo del Prado y dos grandes lienzos de la Adoración de los Pastores y la Adoración de los Reyes de la catedral de Sevilla ${ }^{21}$, son evidentes reclamos de su obra en la España contrarreformista.

Las diferencias del lienzo de Santo Domingo de Sanlúcar de Barrameda con las repeticiones citadas del Museo del Prado y Rubenshuis de Amberes son mínimas para traerlas a consideración. Quizás la leve inclinación de la cabeza de Jesús hacia el pavimento es el único detalle que la diferencia de las anteriores.

Es oportuno recordar otras importantes repeticiones dentro de la producción de Jordaens, con escasas variantes respecto a la que encontramos en la iglesia de Santo Domingo y las aquí reunidas, tales como la Piedad de la Kunsthalle de Hamburgo, con dibujo preparatorio en la National Gallery de Dublín, y otras variantes registradas por D'Hulst al estudiar las pinturas del maestro en $1963 \mathrm{y}$ los dibujos en $1974^{22}$.

Fecha de recepción: 8 de enero de 2018

Fecha de aceptación: 5 de febrero de 2019

${ }^{21}$ ARANA DE VARFLORA, Fermín: Compendio histórico descriptivo de la muy noble y muy leal ciudad de Sevilla metrópoli de Andalucía. Sevilla, 1789, parte I, p. 51; y GESTOSO Y PÉREZ, José: Una requisa de cuadros en la Catedral de Sevilla. Sevilla, 1909, pp. 20 y 27. Vid. DÍAZ PADRÓN, Matías: Pedro Pablo Rubens..., op. cit., p. 69, no 51.

22 D'HULST, R.-A.: "Further Drawings by Jacob Jordaens", Master Drawings, I, 3, 1963, pp. 23-26, figs. 4-6, pls. 13-15; y D'HULST, R.-A.: Jordaens..., op. cit., p. 359, nº A280, fig. 294. 


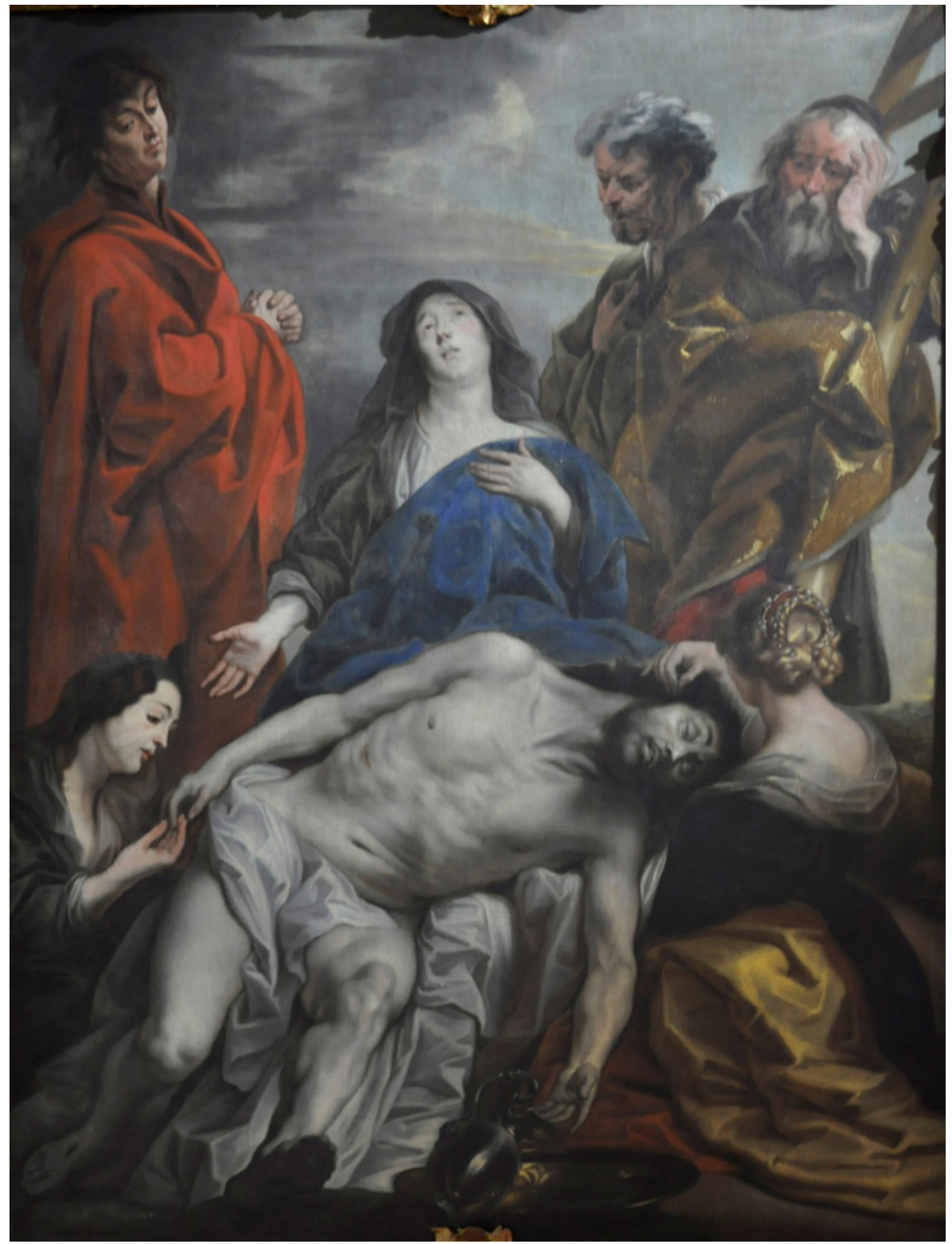

Figura 1. Jacob Jordaens, Piedad, iglesia de Santo Domingo, Sanlúcar de Barrameda (Cádiz). 


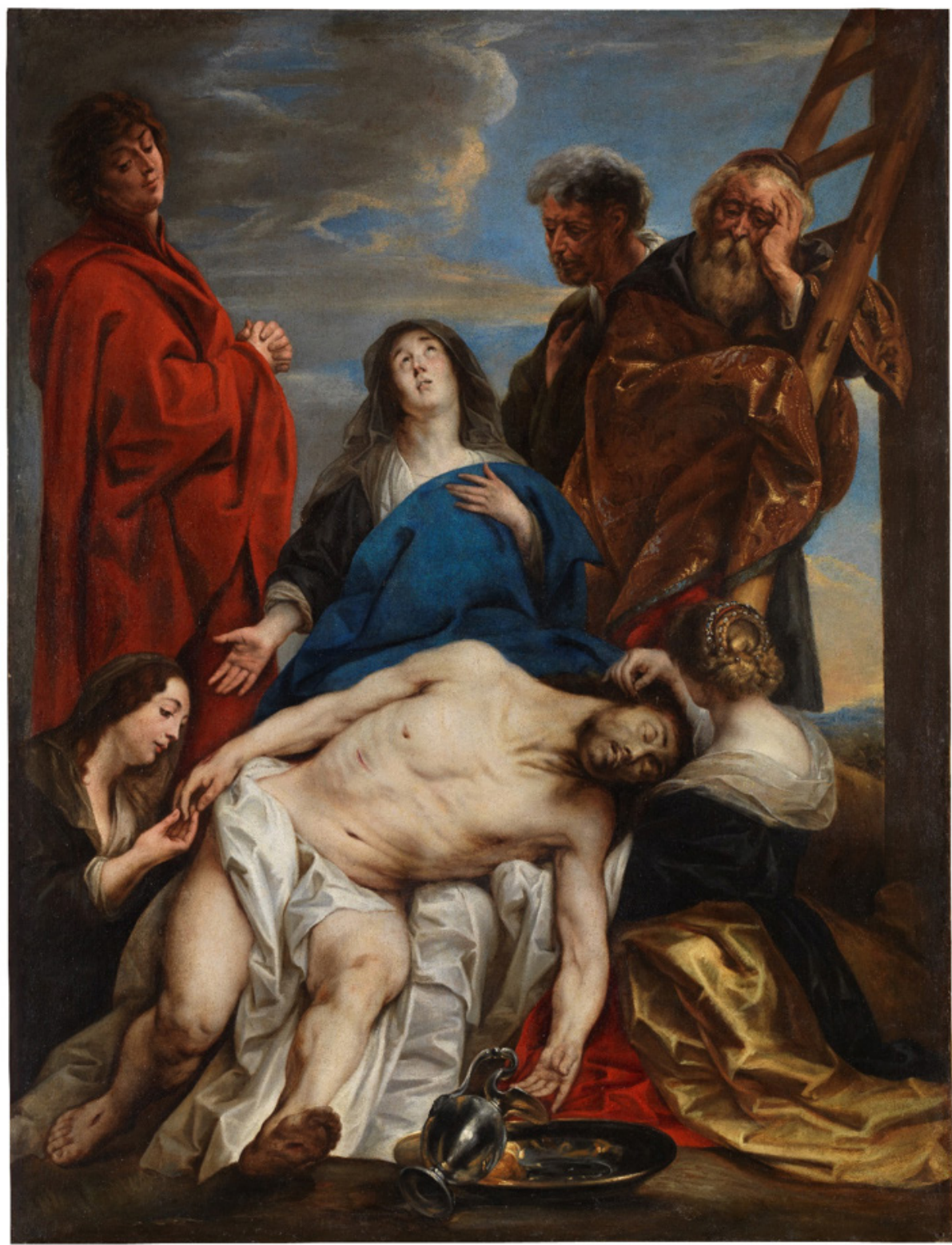

Figura 2. Jacob Jordaens, Piedad, Museo Nacional del Prado, Madrid. 


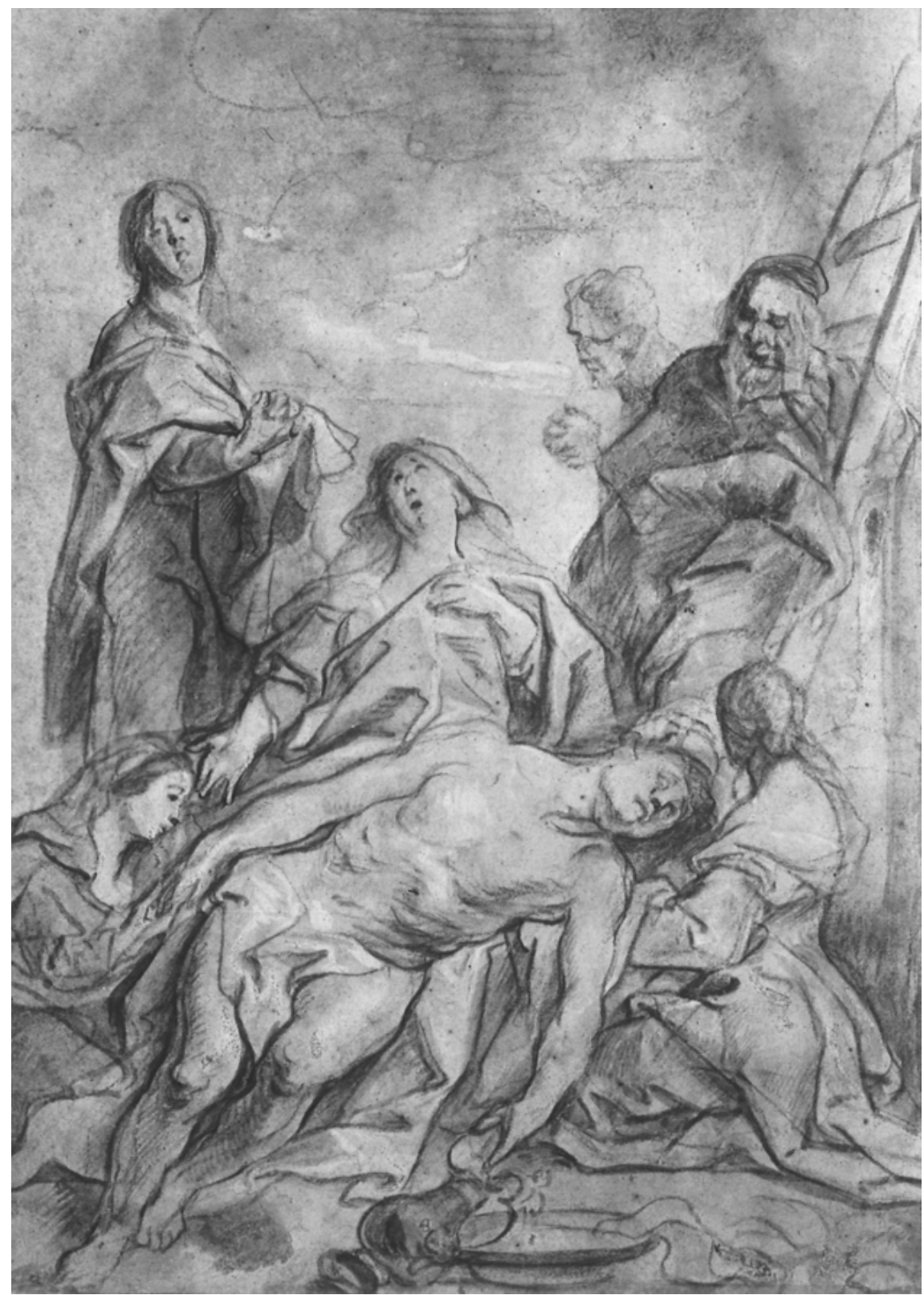

Figura 3. Jacob Jordaens, Piedad, colección Sir Richard Nosworthy, Londres.

LABORATORIO DE ARTE 31 (2019), pp. 641-652, ISSN 1130-5762

e-ISSN 2253-8305 - DOI http://dx.doi.org/10.12795/LA.2019.i31.38 


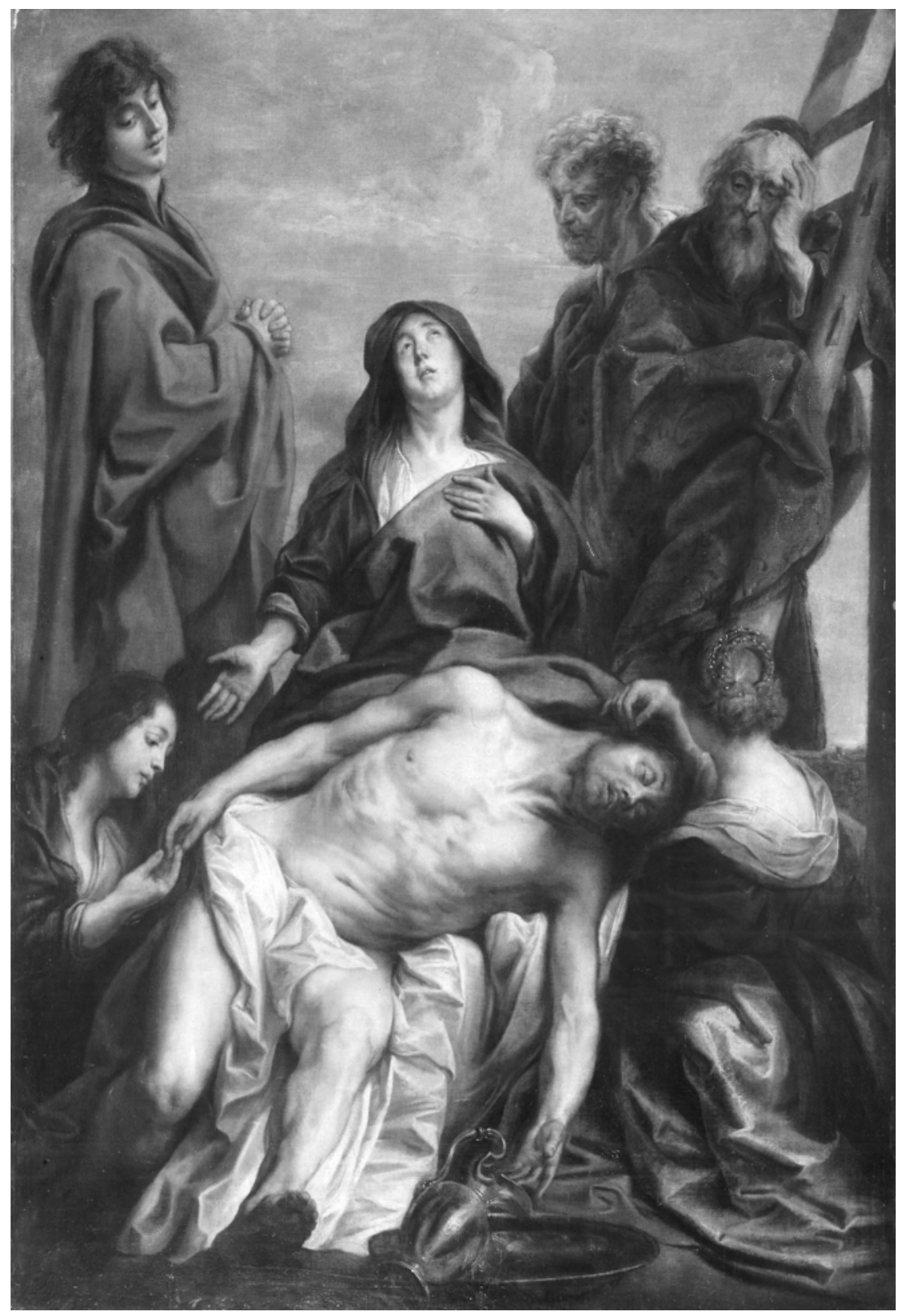

Figura 4. Jacob Jordaens, Piedad, Rubenshuis, Amberes. 


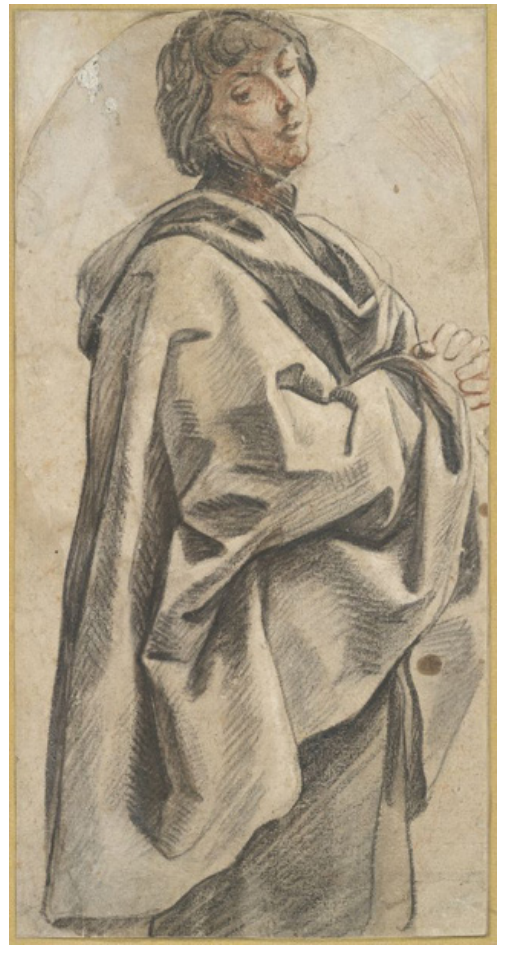

Figura 5. Jacob Jordaens, San Juan, Fogg Art Museum, Cambridge (Massachusetts).

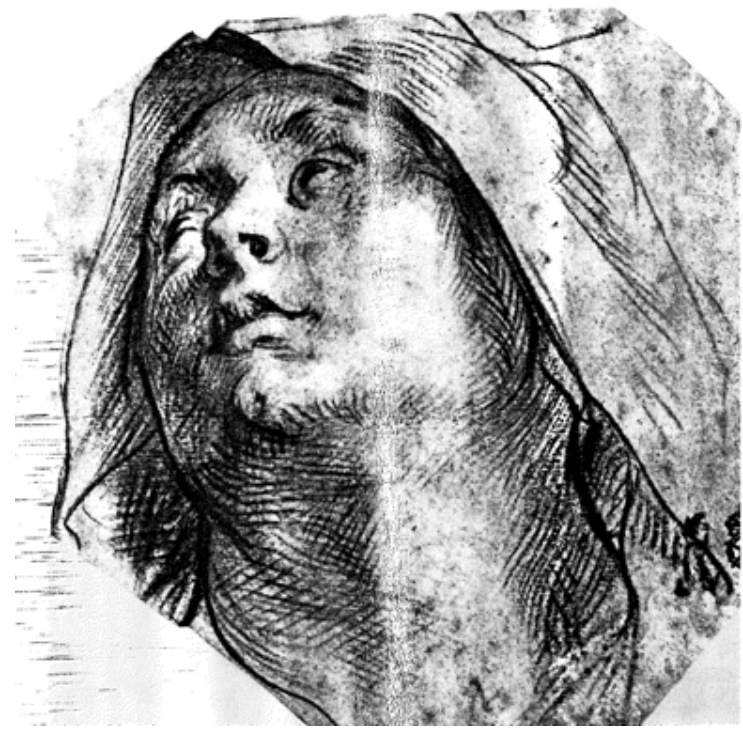

Figura 6. Jacob Jordaens, Rostro de mujer, antigua colección Russell. 